\title{
In-Grove Spatiotemporal Spread of Citrus Huanglongbing and Its Psyllid Vector in Relation to Weather
}

\author{
M. M. Shimwela, ${ }^{1,2}$ S. E. Halbert, ${ }^{3}$ M. L. Keremane, ${ }^{4}$ P. Mears, ${ }^{5}$ B. H. Singer, ${ }^{2}$ W. S. Lee, ${ }^{6}$ J. B. Jones, ${ }^{1}$ \\ R. C. Ploetz, ${ }^{7}$ and A. H. C. van Bruggen $1,2, \dagger$ \\ ${ }^{1}$ Department of Plant Pathology, IFAS, University of Florida, Gainesville 32611; ${ }^{2}$ Emerging Pathogens Institute, University of Florida, \\ Gainesville 32610; ${ }^{3}$ Florida Department of Agriculture and Consumer Services, Division of Plant Industry, Gainesville 32608; ${ }^{4}$ United States \\ Department of Agriculture-Agricultural Research Service, National Clonal Germplasm Repository for Citrus and Dates, Riverside, \\ CA 92507; ${ }^{5}$ Florida Department of Agriculture and Consumer Services, Division of Plant Industry, Immokalee, FL 34142-3829; ${ }^{6}$ Department \\ of Agricultural and Biological Engineering, Gainesville, FL 32611; and 7Plant Pathology Department, TREC, University of Florida, \\ Homestead 33031.
}

Accepted for publication 24 September 2018.

\begin{abstract}
Reports of spatial patterns of 'Candidatus Liberibacter asiaticus'infected asymptomatic citrus trees and ' $\mathrm{Ca}$. L. asiaticus'-positive Asian citrus psyllids (ACP) are rare, as are published relationships between huanglongbing (HLB), ACP, and weather. Here, spatial patterns of ' $\mathrm{Ca}$. L. asiaticus'-positive asymptomatic and symptomatic trees were determined every half year in a small grove over 2.5 years, and of HLB-symptomatic trees and (' $\mathrm{Ca}$. L. asiaticus'-positive) ACP populations every month in

two commercial groves for 1 year. Spread of symptomatic trees followed that of asymptomatic ' $\mathrm{Ca}$. L. asiaticus'-positive trees with $<6$ months' delay. 'Ca. L. asiaticus'-positive asymptomatic and symptomatic fronts moved at 2.5 to $3.6 \mathrm{~m} \mathrm{month}^{-1}$. No spatial relationship was detected between ACP populations and HLB-infected trees. HLB incidence and ' $C a$. L. asiaticus'positive ACP dynamics were tentatively positively correlated with monthly rainfall data and, to a lesser extent, with average minimum temperature.
\end{abstract}

Citrus huanglongbing (HLB) or greening is one of the most destructive citrus diseases worldwide (Gottwald 2010; Shimwela et al. 2016). HLB manifests itself with various symptoms on leaves, fruit, and roots (da Graça et al. 2016). Severely infected trees are sparsely foliated and die back (Gottwald 2010). Major yield losses have been reported for all HLB-affected citrus production areas, including Florida (Farnsworth et al. 2014).

HLB is associated with 'Candidatus Liberibacter asiaticus' in North America. ' $\mathrm{Ca}$. L. asiaticus' has been found mainly in the phloem of citrus trees, although it also can occur in the xylem (Bonani et al. 2010; Ebert et al. 2018). The pathogen is transmitted naturally by the Asian citrus psyllid (ACP) Diaphorina citri Kuwayama (Hall et al. 2012) feeding on the phloem and reproducing on newly developing flushes of young leaves on the expanding terminal ends of shoots (Chiyaka et al. 2012; Hall et al. 2012; Lee et al. 2015; Sétamou et al. 2016). On older leaves, ACP adults probe into the xylem, especially in the off-season (Ebert et al. 2018). Optimal acquisition and transmission of ' $\mathrm{Ca}$. L. asiaticus' requires flush colonization by nymphs (Lee et al. 2015). The period between infection of flush and acquisition of ' $\mathrm{Ca}$. L. asiaticus' by ACP nymphs can be as short as 10 to 15 days (Lee et al. 2015). The life cycle of the psyllids is 15 to 45 days. Thus, the latency period (from infection of a flush to the first new flush infection) can range

†Corresponding author: A. H. C. van Bruggen; E-mail: ahcvanbruggen@ufl.edu

Funding: This work was made possible by the generous support of the American people through the United States Agency for International Development (USAID)funded Innovative Agricultural Research Initiative project (iAGRI) (award number CA-621-A-00-11-00009-00). We are grateful to the Esther B. O'Keeffe Foundation for contributing additional funding to this research.

*The $\boldsymbol{e}$-Xtra logo stands for "electronic extra" and indicates that two supplementary figures and two supplementary tables are published online.

The author(s) declare no conflict of interest.

(c) 2019 The American Phytopathological Society from 3 to 6 weeks (Chiyaka et al. 2012; Lee et al. 2015). The incubation period, from the time of infection until HLB symptom appearance, is substantially longer than the latency period and can vary from a few months to several years (Shen et al. 2013b). The incubation period also depends on the age and nutritional status of the tree (Shen et al. 2013a) and environmental conditions (Gottwald 2010). However, the time from first detection of ' $\mathrm{Ca}$. L. asiaticus' in a tree until first symptom appearance has not been determined under field conditions.

' $\mathrm{Ca}$. L. asiaticus' tolerates a wide range of temperatures up to approximately $35^{\circ} \mathrm{C}$ (Bové 2014) but ' $\mathrm{Ca}$. L. asiaticus' concentrations in ACP and citrus trees decline at $42^{\circ} \mathrm{C}$ (Razi et al. 2014). ACP itself is sensitive to temperatures above $40^{\circ} \mathrm{C}$ (Hall et al. 2011; Hussain et al. 2017). ACP dynamics and spread and potential HLB development have been modeled based on temperature relationships (Aurambout et al. 2009; Gutierrez and Ponti 2013; López-Collado et al. 2013; Torres-Pacheco et al. 2013). However, Narouei-Khandan et al. (2016) determined that the global distributions of ACP and HLB were mainly affected by rainfall and minimum temperature of the coldest month. Thomas et al. (2017) also found a positive association between ACP abundance and precipitation. However, rainfall has not been studied sufficiently in relation to the spread of $\mathrm{ACP}$ and HLB at the grove scale.

Management of HLB has been based primarily on the production of clean nursery stock, removal of symptomatic trees, and intensive use of insecticides (Craig et al. 2018; Gasparoto et al. 2018; Gottwald 2010; Grafton-Cardwell et al. 2013) but has been insufficiently effective to prevent spread of the disease in Florida. HLB management could be improved by a better understanding of the spatial patterns of its spread in relation to environmental variables (Narouei-Khandan et al. 2016).

The spatial pattern of HLB within a grove generally is not random. Initially, affected trees often are more numerous at the edges of a grove (Gasparoto et al. 2018; Gottwald et al. 2010; Leal et al. 2010; Luo et al. 2012; Shen et al. 2013b), and subsequent spread develops from these initial incursions (Bassanezi et al. 2005; 
Gottwald et al. 2007, 2010; Luo et al. 2012). ACP may move more readily among trees within rows than across rows, because there is a stronger within-row than across-row aggregation of HLB (Bassanezi et al. 2005; Gottwald et al. 2007, 2010; Shen et al. 2013b). Experiments where ACP and HLB-symptomatic trees were tested for ' $\mathrm{Ca}$. L. asiaticus' in the same groves have been seldom conducted, and spatial analyses of these data were not carried out (Razi et al. 2014).

Several methods have been used to describe the spatial pattern of ACP and patterns of HLB spread (Flores-Sánchez et al. 2017; Gasparoto et al. 2018; Gottwald et al. 2010; Leal et al. 2010, Luo et al. 2012; Parnell et al. 2011; Shen et al. 2013b). Gradient analysis has been instrumental in estimating the rate of spread of the edge of a grove (Gasparoto et al. 2018). Geostatistical analyses such as spatial autocorrelation and cluster analyses have contributed to a better understanding of spatial patterns of HLB incidence, and kriging interpolation has been employed to predict disease occurrence in unsampled locations (Bouwmeester et al. 2016; Leal et al. 2010, Luo et al. 2012; Nelson and Boots 2008). However, detailed spatial patterns of asymptomatic ' $\mathrm{Ca}$. L. asiaticus'-infected trees and ACP have not been described, and the rate and shape of frontal spread have been rarely calculated at the grove scale (Gasparoto et al. 2018; Leal et al. 2010; Luo et al. 2012; Parnell et al. 2011). Consequently, most models have been validated only with HLB-symptomatic trees, whereas ACP dynamics and spread have been based on data from controlled-environment studies (Chiyaka et al. 2012; Lee et al. 2015).

Considering the above knowledge gaps, this study had the following objectives: (i) determine the temporal gap between the progress curve of ' $\mathrm{Ca}$. L. asiaticus' detection in asymptomatic orange trees and the progress curve of HLB-symptomatic trees, (ii) determine the dynamics and shape of the front of ' $\mathrm{Ca}$. L. asiaticus'-positive trees, (iii) compare the spatial patterns of HLBsymptomatic trees and (' $\mathrm{Ca}$. L. asiaticus'-positive) ACP over time, and (iv) relate the incidence of ' $\mathrm{Ca}$. L. asiaticus'-positive and HLBsymptomatic trees and of ' $\mathrm{Ca}$. L. asiaticus'-positive ACP to seasonal weather data (rainfall, relative humidity and temperature). To address these objectives, we examined HLB symptoms, the presence of ' $\mathrm{Ca}$. L. asiaticus' in asymptomatic and symptomatic citrus trees, ACP populations, and the presence of ' $\mathrm{Ca}$. L. asiaticus' in these populations at two spatial and temporal scales: a small citrus block ( 118 by $85 \mathrm{~m}$ ) in North Florida at 6-month intervals over 2.5 years, and two medium-sized commercial citrus groves (total sampled area of 2.8 by $4.1 \mathrm{~km}$ ) in South Florida at monthly intervals during 1 year. ACP populations were counted in the commercial groves only.

\section{MATERIALS AND METHODS}

Study sites. The first study site was a small Hamlin orange grove located at the University of Florida's Plant Science Research and Education Unit in Citra, FL $\left(29^{\circ} 24^{\prime} 42^{\prime \prime} \mathrm{N}, 82^{\circ} 06^{\prime} 36^{\prime \prime} \mathrm{W}\right)$ (Shen et al. 2013b). The grove (118 by $85 \mathrm{~m}$ ) was planted in 2002 and managed organically until 2011 and conventionally thereafter. Conventional management consisted of the application of herbicides, fertilizers, fungicides, and insecticides on a regular basis (Shen et al. 2013b). In addition, systemic insecticides were applied to the soil for psyllid control. A few ' $\mathrm{Ca}$. L. asiaticus'positive psyllids were detected in the grove for the first time in 2006 but HLB symptoms were not evident until the fall of 2012 (Shen et al. 2013b).

The second study consisted of two adjacent citrus groves ( 250 and 460 ha) in Charlotte County in South Florida. The sampled areas in both groves ( 2.8 by $4.1 \mathrm{~km}$ ) had Valencia and Hamlin orange trees. Grove 1 was managed without the use of synthetic pesticides and fertilizers. Natural undergrowth was cut regularly with machetes, and mulch was applied to the trees. Grove 2 practiced conventional citrus management with insecticide and copper fungicide applications every 4 to 6 weeks, and standard herbicide management of weeds. In the latter grove, HLB-symptomatic trees had been removed and replaced before the study.

Sampling, field observations, and laboratory analyses. In the small Hamlin grove at Citra, FL, a systematic grid-based sampling approach was used to facilitate geostatistical spatial analysis, as described previously (Shen et al. 2013b). In spring and fall 2012 and 2013 and spring 2014, all selected trees were examined for HLB symptoms and leaf samples (Li et al. 2009) were collected from the selected trees regardless of the presence of visual symptoms. Real-time polymerase chain reaction(PCR) analysis of the first samples indicated that the pathogen occurred in the eastern rows only, and moved from east to west. Therefore, in addition to the systematically selected trees throughout the grove, complete rows were sampled from east to west until all trees in a row tested negative. Leaf samples were brought to the laboratory of the Emerging Pathogens Institute, University of Florida, in Gainesville, for DNA extraction and ' $C a$. L. asiaticus'-specific quantitative (q) PCR. At the end of study period, all trees in the grove had been tested for ' $\mathrm{Ca}$. L. asiaticus' and inspected for symptoms. Details of the sampling procedure are given in the supplementary materials.

In each of the two commercial groves in South Florida, four blocks (approximately 400 by $500 \mathrm{~m}$ ) were selected randomly (one with Hamlin and three with Valencia trees). Monthly surveys were conducted from 1 July 2009 to 31 August 2010. Selected trees were checked for the numbers of mature and young flushes; presence of psyllid eggs, nymphs, and adults; and HLB symptoms. Details of the sampling procedure are given in the supplementary materials. The presence of ' $\mathrm{Ca}$. L. asiaticus' in HLB-symptomatic trees was confirmed by qPCR in the diagnostic clinic of the Florida Department of Agriculture and Consumer Services, Division of Plant Industry (DPI), in Gainesville, during the first 2 months of sampling (confirming that visual detection of HLB coincided with positive qPCR tests). ACP adults, nymphs, and eggs were counted and adults and nymphs were sent to the United States Department of Agriculture (USDA) lab in Riverside, CA, to be tested for ' $\mathrm{Ca}$. L. asiaticus' by conventional PCR and qPCR.

DNA extraction from leaf and psyllid samples. DNA from leaf samples (Fujikawa et al. 2013) from the small Hamlin grove was extracted with a DNeasy Plant Mini Kit (Qiagen Inc., Valencia, CA, USA), as described previously (Shen et al. 2013b). Total DNA was purified with a silica-based membrane and Qiagen elution reagent. DNA extractions from samples collected in the two medium-sized groves were extracted following USDA protocols $(\mathrm{Li}$ et al. 2006). DNA from single or multiple psyllid nymphs or adults per location was extracted according to Manjunath et al. (2008). ACP DNA was used for conventional PCR amplification, as well as qPCR. Details of the DNA extraction procedure and qPCR analyses are given in the supplementary materials

Real-time qPCR of leaf DNA and conventional and qPCR of ACP DNA. Real-time qPCR of leaf DNA from the small-scale experiment was carried out using a CFX96 Real-Time PCR Detection System (Bio-Rad Laboratories, Hercules, CA, USA) according to Li et al. (2006). The primer pair HLBas and $\mathrm{HLBr}$ and a TaqMan probe HLBp were used to amplify the $16 \mathrm{~S}$ ribosomal RNA (rRNA) gene of ' $\mathrm{Ca}$. L. asiaticus', and additional primers for the COX gene were used for a positive internal control (Li et al. 2006). Data analysis was performed with CFX Manager Software (version 2.0; Bio-Rad Laboratories). DNA extracted from the larger-grove leaf samples submitted to DPI was subjected to qPCR for ' $C a$. L. asiaticus' detection using the USDA protocols of Li et al. (2006) and a Cepheid SmartCycler (Cepheid, Sunnyvale, CA, USA). Detailed experimental conditions are given in the supplementary materials. Cycle threshold $(\mathrm{Ct})$ values smaller than 34 were considered positive.

DNA extracted from ACP was amplified by conventional PCR with primers OI1/OI2c and OA1/OI2c, as described previously (Manjunath et al. 2008). Real-time qPCR was performed as 
described in detail by Manjunath et al. (2008). The primer pair HLBas and HLBr and Taqman probe HLBp were used for PCR amplification to target the $16 \mathrm{~S}$ rRNA gene of ' $\mathrm{Ca}$. L. asiaticus' ( $\mathrm{Li}$ et al. 2006). Real-time qPCR was carried out in an ABI ViiA7 machine (Manjunath et al. 2008), with slight modifications. Dilutions of a plasmid with ' $C a$. L. asiaticus' 16 s (1,167-bp insert) were used as positive control for ' $\mathrm{Ca}$. L. asiaticus' (https://www. ncbi.nlm.nih.gov/nuccore/EU130556.1). Ct values smaller than 30 were considered positive. The $\mathrm{Ct}$ values of the negative controls varied between 30 and 40 .

Weather data. For the small-scale study, monthly total rainfall, monthly average relative humidity, and monthly average minimum and maximum temperature data in 2012, 2013, and 2014 were downloaded from the Florida Automated Weather Network (FAWN) database for the weather station at Citra. FAWN provides summarized data for a month before the day indicated in the tables; thus, on 1 January 2012, the average data for December 2011 are given. For the medium-scale study, similar summarized weather data were downloaded for each month of ACP sampling and HLB observation in 2009 and 2010 from the nearest FAWN weather station at Arcadia, FL, $24 \mathrm{~km}$ north of the research site with the two commercial groves in Charlotte County. The weather station and the commercial groves are located in the same temperature and rainfall regions as assessed by kriging of the FAWN weather data (Shimwela et al. 2018).

Preparation of ACP and HLB data for geostatistical and temporal analyses. In the small-scale study, trees on a given sampling date were either negative or positive for ' $\mathrm{Ca}$. L. asiaticus' (qPCR Ct values smaller or larger than 34, respectively) and did or did not have HLB symptoms. Once positive for ' $\mathrm{Ca}$. L. asiaticus' or HLB symptoms, a tree was considered positive for the rest of the study. The binomial data were subjected to kriging (see Geostatistical analysis section) for each observation date (Figs. 1 and 2). Epidemic fronts were calculated from the isolines with the highest probabilities (0.75 to 1.0$)$ and the lowest probabilities ( 0 to 0.25 ) of ' $\mathrm{Ca}$. L. asiaticus'-positive asymptomatic and HLB-symptomatic trees as obtained from kriging (Figs. 1 and 2). The distances from the eastern edge of the grove (where the first positive trees were detected) to these isolines were measured at the center and northern and southern edges of the grove on printed maps (Supplementary Tables S1 and S2); they were averaged and considered the front distances.

In the medium-scale study, total ACP numbers and numbers of ' $C a$. L. asiaticus'-positive ACP as well as the presence or absence of HLB-symptomatic trees were summarized per observation point in each grove and in each month of observation. The quantitative ACP data and binomial HLB data were subjected to kriging per quarter (summer, spring, fall, and winter). The summer included June, July, and August; the fall was September, October, and November; the winter was December and January; and the spring (when most flushes were observed) included February through May. The proportions of ' $\mathrm{Ca}$. L. asiaticus'-positive ACP and of trees with ' $\mathrm{Ca}$. L. asiaticus'-positive ACP, as well as the proportion of observation points positive for HLB, were calculated for each month of observation. ACP and HLB data were plotted over time, together with the rainfall, relative humidity, and temperature data.

Geostatistical analysis. Ordinary kriging was employed in both studies to analyze the pattern of HLB and ACP spread and to obtain the best linear unbiased estimates of the variables at unsampled locations $\left(\mathrm{s}_{0}\right)$ (Bouwmeester et al. 2016; Leal et al. 2010; Luo et al. 2012; Nelson and Boots 2008; Smith et al. 2007).

In ordinary kriging, estimates $\hat{Z}\left(\mathrm{~s}_{0}\right)$ for each variable at any location were derived from linear combinations of the neighboring measured values $\left(\mathrm{s}_{\mathrm{i}}\right)$ according to the following equation:

$$
\hat{\mathrm{Z}}\left(\mathrm{s}_{0}\right)=\sum_{\mathrm{i}=1}^{\mathrm{n}} \lambda \mathrm{iZ}(\mathrm{si})
$$

where $\mathrm{Z}\left(\mathrm{s}_{\mathrm{i}}\right)$ is the sample value at location $i, \lambda_{\mathrm{i}}$ is a weight, $n$ is the number of samples, $\mathrm{s}_{0}$ is a prediction location, and $n$ is the number of measured values. This estimation is unbiased and has minimum variance (Johnston et al. 2001). Ordinary kriging assumes a constant but unknown mean and fits a mathematical function to a specified number of points to determine the output values for all surrounding locations as follows:

$$
\mathrm{Z}_{(\mathrm{s})}=\mu+\varepsilon_{(\mathrm{s})}
$$

where $\varepsilon_{(\mathrm{s})}$ is a zero mean second-order stationary random field with covariogram function $\mathrm{C}_{(\mathrm{h})}$ and variogram $\gamma_{(\mathrm{h})}$ (Johnston et al. 2001). Ordinary kriging was performed with the geostatistical Analyst tool in ArcGIS 10.3.1. Semivariograms were prepared by fitting the spherical model (Shen et al. 2013b), which was selected based on an average error close to 0 and a root mean square error standardized close to 1 (Johnston et al. 2001). The anisotropy effect also was checked (Shimwela et al. 2018). Because ordinary kriging is an exact interpolator, meaning that the predicted value is equal to the measured value at the sampled locations, the predicted spatial pattern could be highly clustered (Johnston et al. 2001). To limit the importance of individual values the maximum neighborhood was set to search a radius of five points with a minimum of two points (Shimwela et al. 2018).

Temporal statistical analysis. For the small-scale study, the average front distances were plotted versus the number of months since the start of the study. The rates of spread of the average fronts (with low and high probabilities of ' $\mathrm{Ca}$. L. asiaticus'-positive asymptomatic and of symptomatic trees) were calculated from linear regression in Microsoft Excel 2013.

The proportions of trees that tested positive for ' $\mathrm{Ca}$. L. asiaticus' and that had HLB symptoms were calculated and plotted over time. The proportions of ' $C a$. L. asiaticus'-positive asymptomatic and symptomatic trees in the grove were plotted over time. When skewed sigmoid curves became apparent, the proportions were transformed according to the Gompertz equation and regressed on the number of months since observations were started using PROC REG in SAS (version 9.4; SAS Institute, Inc., Cary, NC, USA). The predicted data were back-transformed and plotted over time, together with the original data. The back-transformed predicted data were also regressed on the observed data to obtain a recalculated $R^{2}$. The epidemic rates were back-transformed from the estimated relative rates in the Gompertz equation. Pearson correlations were calculated in Excel 2013 for the 6-monthly increase in the proportions of ' $\mathrm{Ca}$. L. asiaticus'-positive and of HLB-symptomatic trees versus the monthly total rainfall, monthly average relative humidity, and monthly average minimum and maximum temperature in the month prior to each sampling and HLB observation date. In addition, the 6-monthly increases in ' $\mathrm{Ca}$. L. asiaticus'-positive and HLB-symptomatic trees were correlated to the average weather data over the 6 months between successive samplings and observations. For the calculation of $P$ values, $t$ tests were carried out as an intermediate step.

In the commercial grove study, the rate of spread of ACP populations and HLB-symptomatic trees could not be estimated because the epidemic was established already at the time of sampling in both groves. Total and ' $\mathrm{Ca}$. L. asiaticus'-positive ACP populations per tree and the proportion of observation points with HLB-symptomatic trees were plotted over time, together with total monthly rainfall, average monthly relative humidity, and average monthly minimum and maximum temperatures for the month prior to observation and sampling. These ACP and HLB data were subjected to linear regression against rainfall, relative humidity, and minimum or maximum temperature in Microsoft Excel 2013. The total numbers of ACP and the proportions of psyllids carrying ' $\mathrm{Ca}$. L. asiaticus' as well as the proportions of trees with HLB symptoms were compared between the two groves using paired $t$ tests in Excel 2013.

Multivariate statistical analysis. The relatively large number of variables and repeated observations over time in the 
medium-scale study lent themselves to multivariate analysis with a sufficient number of degrees of freedom. The objective of this analysis was to detect environmental variables that were associated with ' $\mathrm{Ca}$. L. asiaticus' presence in ACP and HLB symptoms in the trees. The general health status and size of each tree, the number of mature and young flushes, presence of ACP nymphs and adults, monthly total rainfall, and monthly average minimum temperature and maximum temperature data were considered as environmental variables to understand associations with ' $\mathrm{Ca}$. L. asiaticus'-positive ACP and HLB symptoms in space and time. Because both quantitative and qualitative variables were included, canonical correspondence analysis was selected (Savary et al. 1995), using the Past program, version 3.11 (folk.uio.no/ohammer/past).

\section{RESULTS}

Small-scale study. In spring 2012, no symptoms of HLB were evident (Fig. 1A), even though ' $\mathrm{Ca}$. L. asiaticus' was detected in 33

\section{A
C}
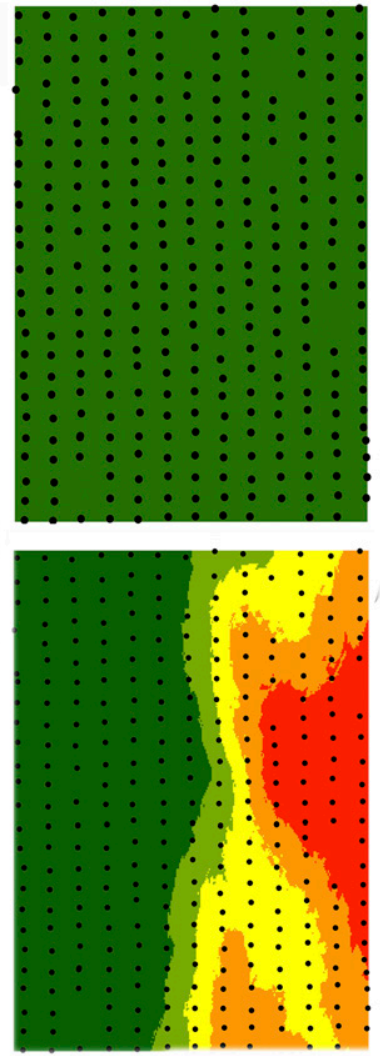

E

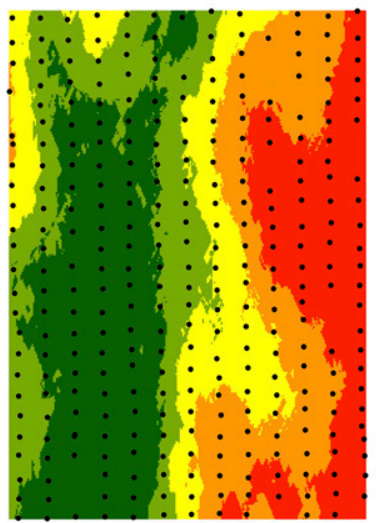

B

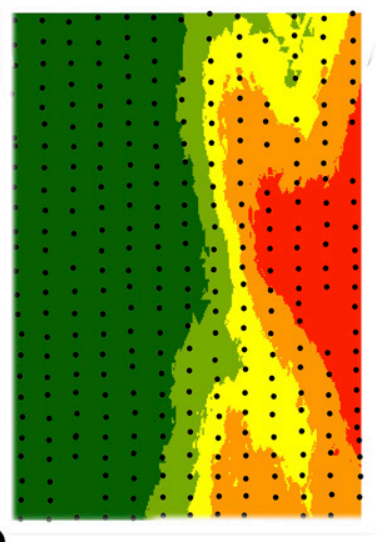

D
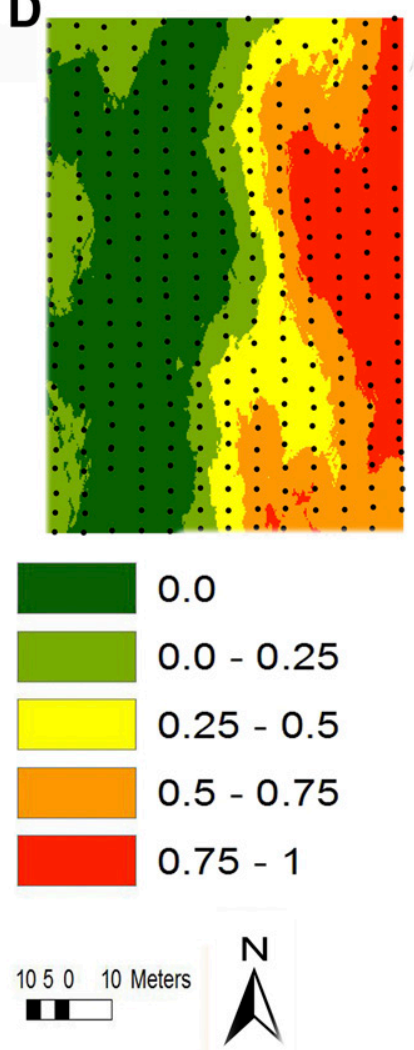

Fig. 1. Kriged probabilities of Hamlin orange trees with huanglongbing symptoms in a small block in Citra, FL, in A, April 2012; B, October 2012; C, April 2013; D, October 2013; and E, April 2014. trees in the first two rows on the east side of the grove (Fig. 2A). In fall 2012, 'Ca. L. asiaticus' was detected in 60 trees in four rows (Fig. 2B), and some ' $\mathrm{Ca}$. L. asiaticus'-infected trees began to display HLB symptoms (Fig. 2B). In spring 2013, the distribution of trees with ' $\mathrm{Ca}$. L. asiaticus' shifted toward the southwest (Fig. 2C), and this was reflected in the distribution of symptoms, although these still lagged behind ' $\mathrm{Ca}$. L. asiaticus' infection (Fig. 1C). In fall 2013, some symptomatic trees were observed on the west side of the grove, while the trees in the middle rows were still asymptomatic (Fig. 1D) and the ' $C a$. L. asiaticus'-positive trees were still primarily located on the east side of the grove (Fig. 2D). By spring 2014, both symptomatic and ' $C a$. L. asiaticus'-positive trees occurred on the west side of the grove (Figs. 1E and 2E), while the central rows were still largely unaffected. This suggested that the psyllids had not moved gradually from row to row but, perhaps, had jumped to the west side or entered on the western margin in the fall of 2013 .
A

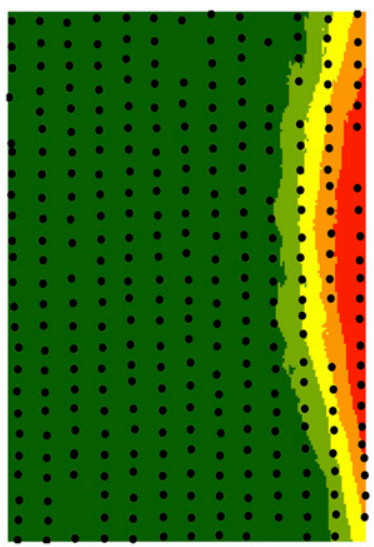

C

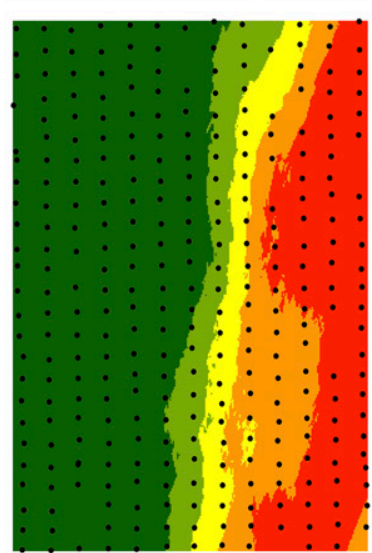

$\mathbf{E}$

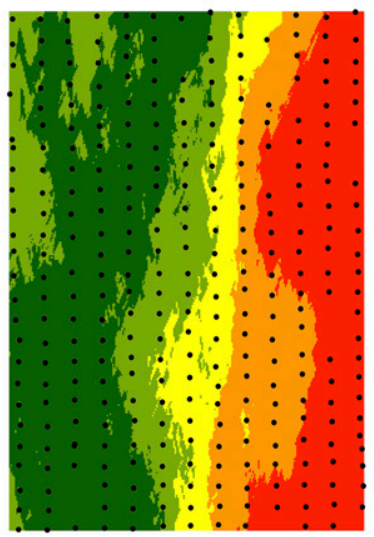

B

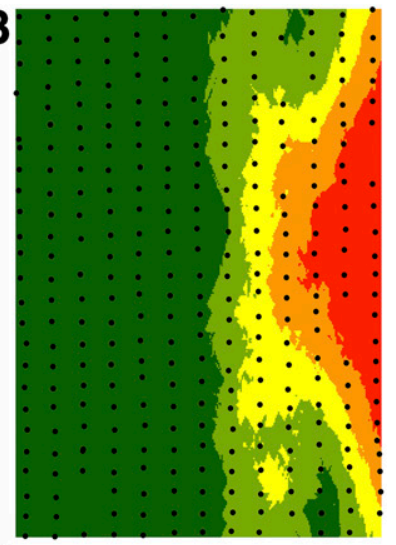

D

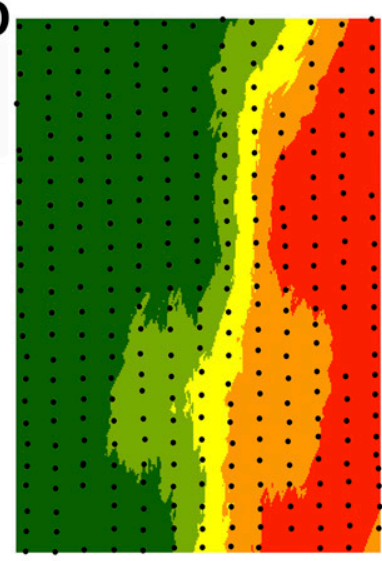

0.0
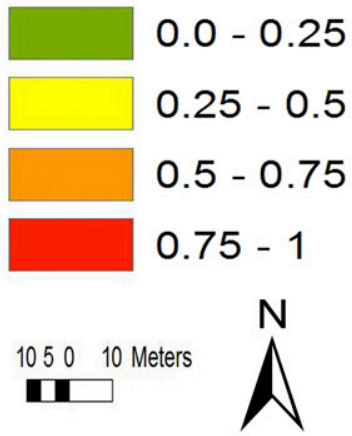

Fig. 2. Kriged probabilities of Hamlin orange trees that tested positive for 'Candidatus Liberibacter asiaticus' with quantitative polymerase chain reaction in a small block in Citra, FL, in A, April 2012; B, October 2012; C, April 2013; D, October 2013; and E, April 2014. 
Plotting the proportions of ' $\mathrm{Ca}$. L. asiaticus'-positive and symptomatic trees over time indicated that the progress curve for ' $C a$. L. asiaticus' was ahead of that for HLB symptoms until November 2013, when symptom development outpaced ' $C a$. L. asiaticus' detection (Fig. 3). The relative rates of disease progress were 0.047 and 0.051 month $^{-1}$ for ' $C a$. L. asiaticus'-positive trees and of HLB-symptomatic trees, respectively. The faster appearance of symptoms relative to detection of ' $\mathrm{Ca}$. L. asiaticus' can also be seen in the plots of the distance of the epidemic front over time, with a steeper slope of the front for the low-probability isolines of the HLB symptoms than of ' $\mathrm{Ca}$. L. asiaticus' detection (Figs. 1, 2, and 4). The distance to the low-probability, furthest front increased linearly with time with a rate of $2.5 \mathrm{~m} \mathrm{month}^{-1}$ for ' $\mathrm{Ca}$. L. asiaticus' detection and $3.6 \mathrm{~m} \mathrm{month}^{-1}$ for HLB symptom appearance (Fig. 4).

The annual weather pattern was as usual for Florida, with high rainfall in July and August; the highest minimum and maximum temperatures in June, July, August. and September; and a high relative humidity during most of the year (Supplementary Fig. S1). In the beginning of 2013, the rainfall was slightly lower than normal and the winter temperature was also lower, including night frost. The average weather data during the month prior to field observation and sampling were not related to the half-yearly increase in HLB symptom development or in the proportion of ' $\mathrm{Ca}$. L. asiaticus'-positive trees, except for rainfall, which was positively correlated $(r=0.72 ; P=0.07)$ with the increase in the proportion ' $C a$. L. asiaticus'-positive trees (five observation times). Rainfall over the 6-month period prior to observation was positively correlated with the increase in proportion of symptomatic trees $(r=0.79 ; P=0.03)$ but not with the increase in the proportion of ' $C a$. L. asiaticus'-positive trees. Average maximum and minimum temperatures 6 months prior to sampling were negatively correlated ( $r=-0.79$ and -0.81 , respectively; $P=0.04$ and 0.03 , respectively) with the increase in ' $\mathrm{Ca}$. L. asiaticus'-positive trees over that 6month period. The negative correlations reflect that the differences in qPCR values were greater after a winter period with relatively low minimum and maximum temperatures.

Commercial grove study. HLB-affected trees were initially more widely distributed in grove 2 (conventional management) than in grove 1 (low-input management) but remained more or less constant over time in grove 2 , whereas they increased in grove 1 (Fig. 5A, D, G, J, and M). Thus, ' $\mathrm{Ca}$. L. asiaticus' may have first

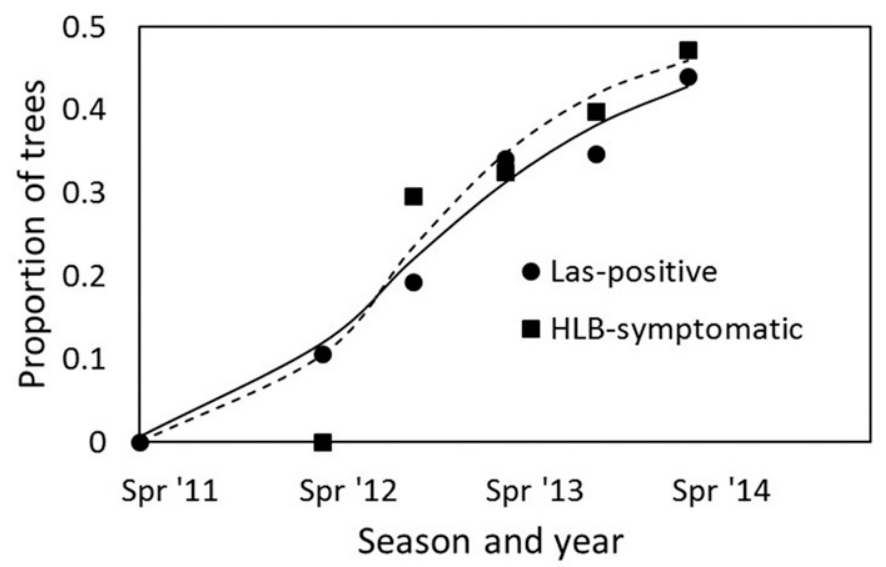

Fig. 3. Proportion of Hamlin orange trees that tested positive for 'Candidatus Liberibacter asiaticus' (Las) and the proportion that displayed typical huanglongbing (HLB) symptoms in Citra, FL, over a period of 2.5 years (from spring 2012 to spring 2014; ' $\mathrm{Ca}$. L. asiaticus' and HLB incidence were assumed to be 0 in spring 2011). Equations for fitting the Gompertz curves (with an asymptote of 1.0 and 6-month time intervals) were $-\ln [-\ln$ (prop) $]=0.5558$ (time) $-1.4711\left(R^{2}=0.971\right)$ for the proportion of ' $C a$. L. asiaticus'-positive trees and $-\ln [-\ln ($ prop$)]=0.7244$ (time) $-1.8913\left(R^{2}=0.889\right)$ for the proportion of HLB-symptomatic trees. Back-transformed relative disease progress rates were 0.047 month $^{-1}$ for the proportion of ' $\mathrm{Ca}$. L. asiaticus'-positive trees and 0.051 month $^{-1}$ for the proportion of HLB-symptomatic trees. entered the area in grove 2. ACP was controlled in that grove with insecticides once symptoms were observed, after large areas already were infested. The trees in grove 1 initially were largely symptom free (Fig. 5A) but succumbed rapidly to HLB after ' $\mathrm{Ca}$. L. asiaticus' infection started (Fig. $5 \mathrm{G}, \mathrm{J}$, and M). The proportion of observation points with HLB symptoms was 0.42 (grove 1 ) and 0.50 (grove 2) in August 2009, and 0.83 (grove 1) and 0.63 (grove 2) in August 2010 (Fig. 6A). The average proportions from September 2009 onward were $0.68 \pm 0.03$ and $0.47 \pm 0.04$ for grove 1 and grove 2 , respectively, which were significantly different from each other $(P=0.001)$. There were no significant associations $(P>0.05)$ between the proportion of HLB-positive trees and monthly rainfall, relative humidity, or temperature (Fig. 6A).

ACP numbers were significantly $(P=0.004)$ greater in commercial grove $1(8.5 \pm 1.4$ per tree) than in grove $2(2.9 \pm$ 0.8 per tree), and varied in space and over time, especially in grove 1. Generally, ACP moved from the east side of grove 1 (Fig. $5 \mathrm{~B}$ ), in an area with a relatively high proportion of symptomatic trees, to the center of grove 1 (Fig. 5E, H, K, and N), where more trees became symptomatic over the whole observation period (Fig. 5D, G, J, and M). The location of ACP populations in the groves did not change after September 2009. There were no significant associations $(P>0.05)$ between total ACP numbers and monthly rainfall, relative humidity, or temperature (Supplementary Fig. S2).

Over the whole observation period, the average numbers of ' $\mathrm{Ca}$. L. asiaticus'-positive ACP per season were significantly $(P=0.03)$ higher in grove $1(110 \pm 43)$ than in grove $2(54 \pm 37)$. Areas with high concentrations of ' $\mathrm{Ca}$. L. asiaticus'-positive ACP shifted over time from the northeast to northwest (Fig. 5C, F, I, L, and O), and the
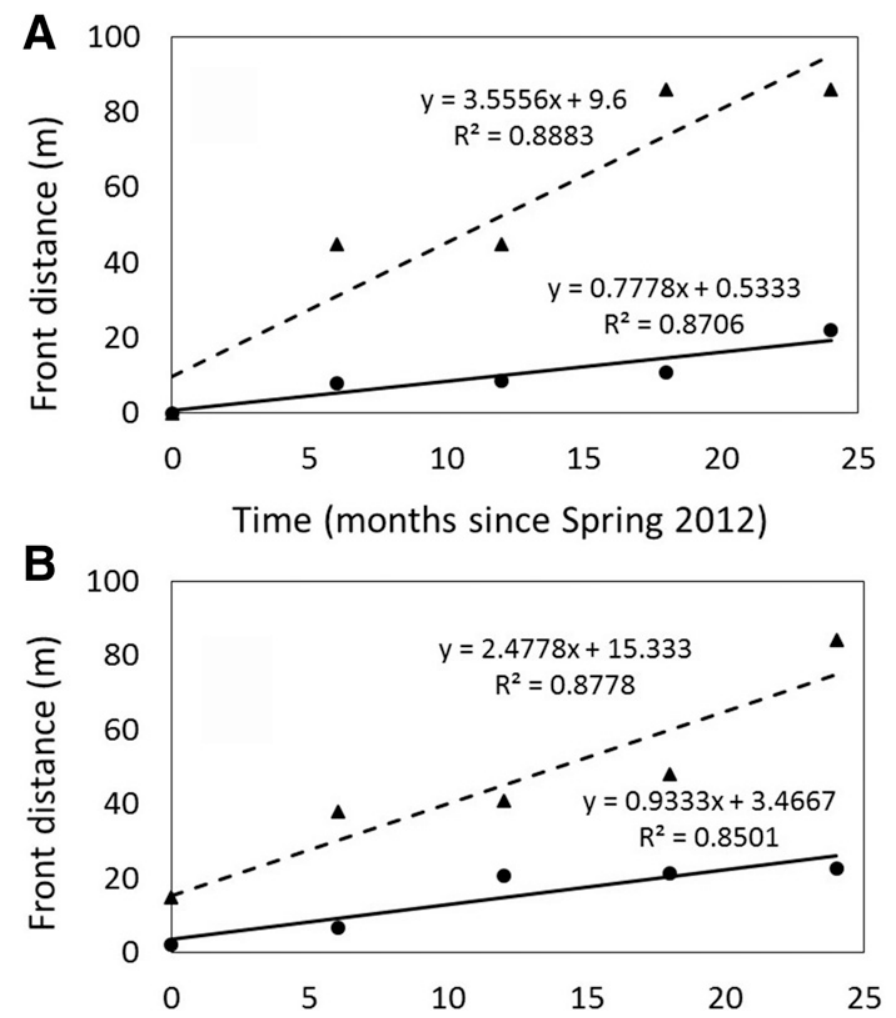

Time (months since Spring 2012)

Fig. 4. Distance of the front of $\mathbf{A}$, huanglongbing-symptomatic and $\mathbf{B}$, 'Candidatus Liberibacter asiaticus'-positive Hamlin citrus trees from the Eastern edge of the grove in Citra, FL, over a period of 2 years. Circles and solid lines represent the average front of the distributions of high probability based on kriging of the observed distributions. Triangles and dotted lines represent the average front of the distributions of low probability based on kriging of the observed distributions. 
proportion of the total ACP that was ' $\mathrm{Ca}$. L. asiaticus' positive varied from 0 to more than half in both groves but did not differ significantly between groves. The highest proportions were found in the summer months (Fig. 6B) with the highest rainfall, and the proportion of ' $\mathrm{Ca}$. L. asiaticus'-positive ACP was positively correlated with monthly rainfall in groves 1 and $2(r=0.66$ and
0.70 , respectively; $P=0.03$ and 0.01 , respectively). The total numbers of ' $\mathrm{Ca}$. L. asiaticus'-positive psyllids were similarly correlated with rainfall (data not shown). Very similar temporal patterns were found when the proportions of trees with ' $\mathrm{Ca}$. L. asiaticus'-positive ACP were plotted over time for each grove (data not shown), and correlations with rainfall were also similar $(r=0.58$

\section{A}

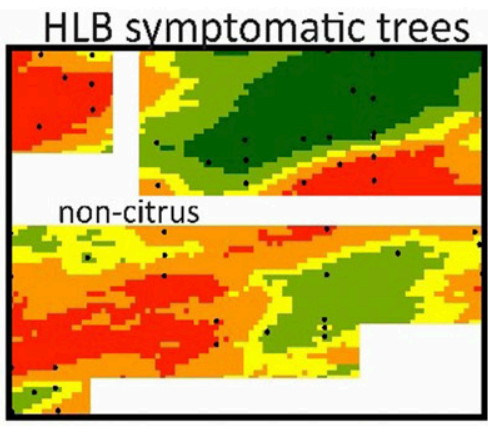

D
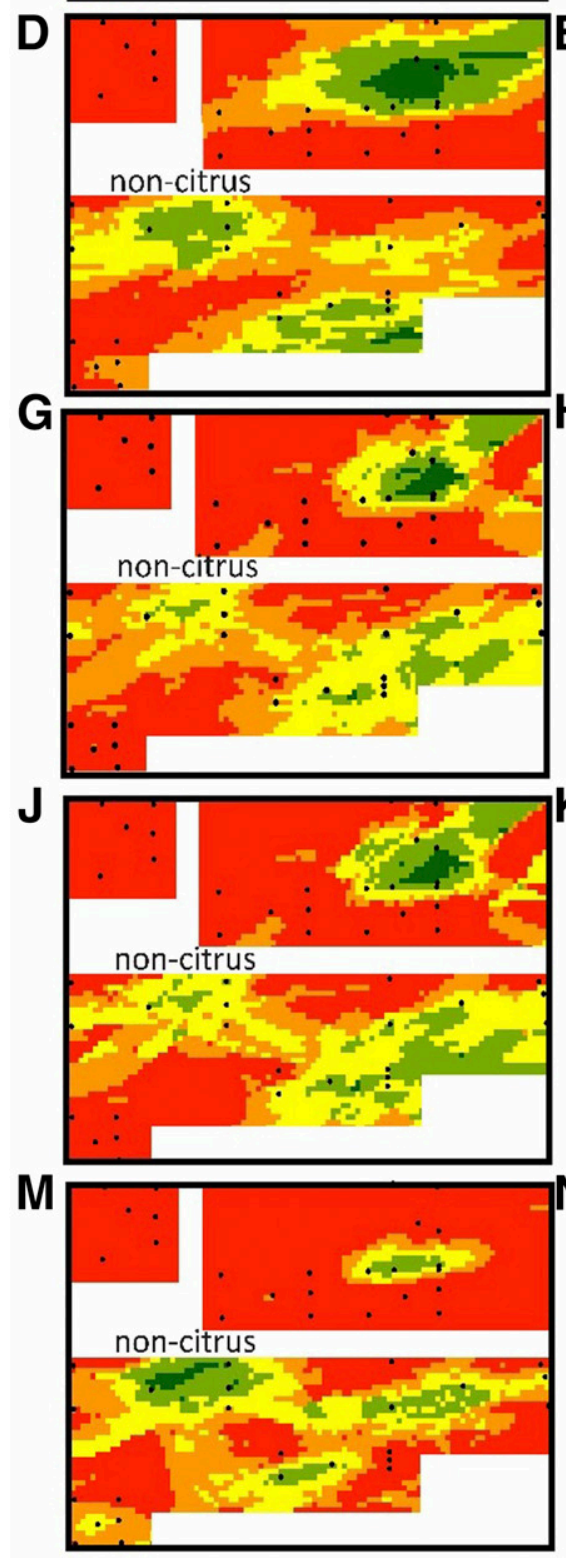

$B$
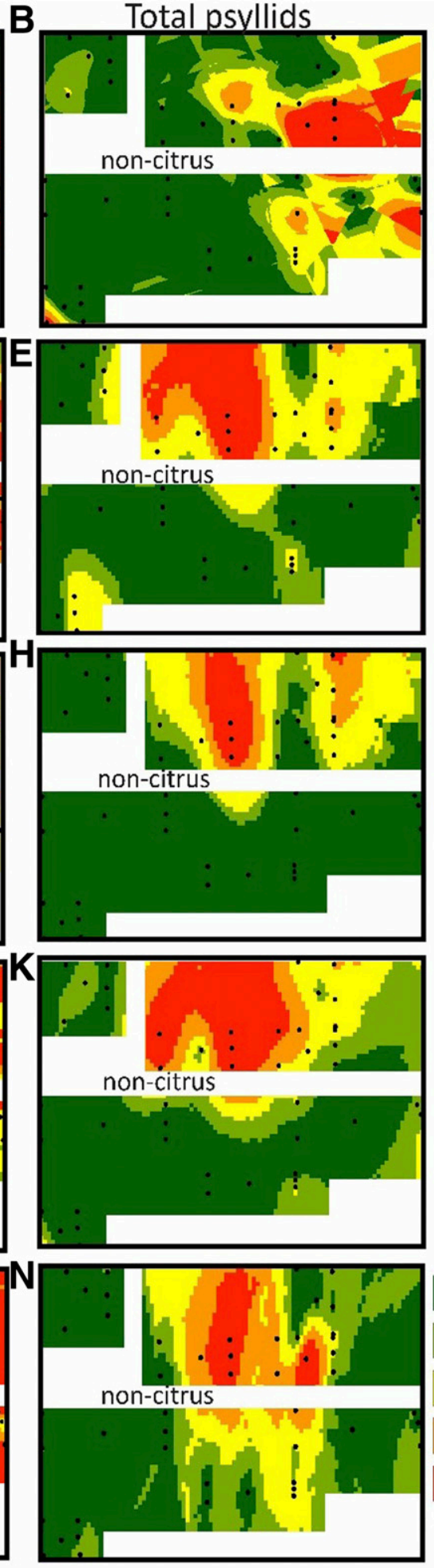
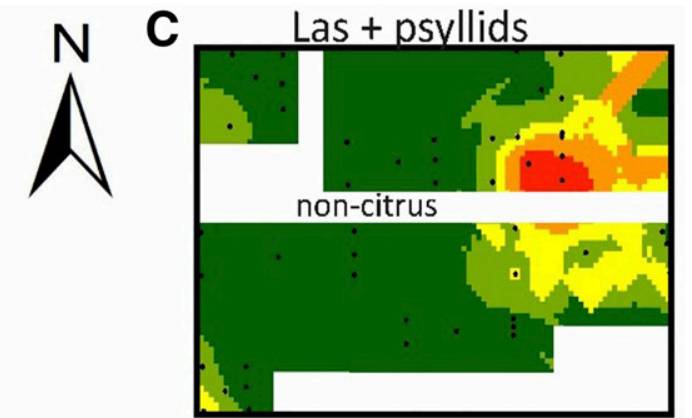

$\mathbf{F}$

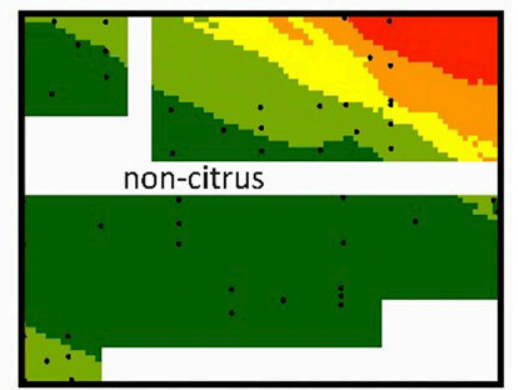

I

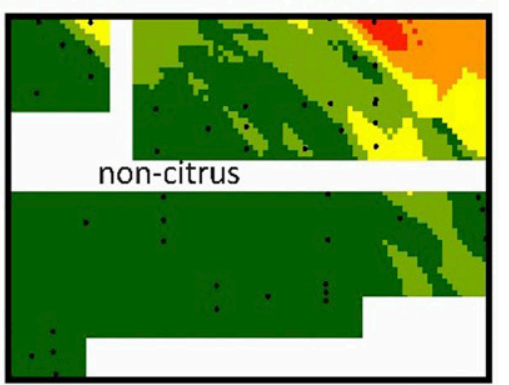

$\mathbf{L}$
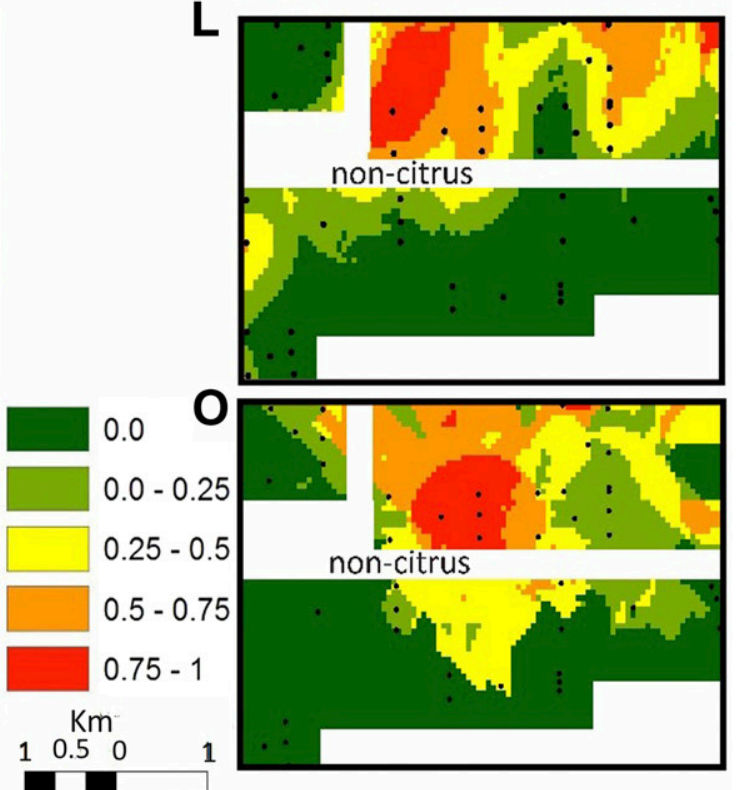

Fig. 5. Probabilities of $\mathbf{A}, \mathbf{D}, \mathbf{G}, \mathbf{J}$, and $\mathbf{M}$, huanglongbing (HLB)-symptomatic orange trees per season; $\mathbf{B}, \mathbf{E}, \mathbf{H}, \mathbf{K}$, and $\mathbf{N}$, total number of psyllids (Diaphorina citri Kuwayama) per season; and $\mathbf{C}, \mathbf{F}, \mathbf{I}, \mathbf{L}$, and $\mathbf{O}$, 'Candidatus Liberibacter asiaticus' (Las)-positive psyllids per season in two neighboring citrus groves (grove 1, north of the noncitrus separation line and grove 2, south of the noncitrus line) in Charlotte County, southern Florida, in summer 2009 (A, B, and C), fall 2009 (D, E, and F), winter 2009-10 (G, H, and I), spring 2010 (J, K, and L), and summer 2010 (M, N, and O). 
and 0.65 for grove 1 and 2 , respectively; $P=0.06$ and 0.02 , respectively). There were no significant associations $(P>0.05)$ with minimum or maximum temperature or relative humidity (data not shown).

Canonical correspondence analysis showed that rainfall and, to a lesser extent, minimum temperature were positively associated with ' $C a$. L. asiaticus'-positive nymphs per grove and per month and with ' $C a$. L. asiaticus'-positive ACP (nymphs and adults), respectively, but not with young or mature flushes or with HLBsymptomatic trees (Fig. 7). The highest numbers of young flushes were observed in February (Julian day 406), when the maximum and minimum temperatures started to increase after winter. Trees with HLB symptoms were not associated with any variable.

\section{DISCUSSION}

The major findings of this research include (i) the time between ' $C a$. L. asiaticus' detection and the appearance of visible symptoms was 6 months or less but the sampling frequency was not high enough to estimate the incubation period, (ii) the moving rates of 'Ca. L. asiaticus'-positive asymptomatic and symptomatic fronts were similar at approximately $3 \mathrm{~m} \mathrm{month}^{-1}$, (iii) there was no direct spatial relationship between ' $C a$. L. asiaticus'-positive ACP populations and HLB incidence in commercial groves, and (iv) positive associations were found between HLB incidence and rainfall as well as ' $\mathrm{Ca}$. L. asiaticus'-positive ACP and rainfall, as described previously (Narouei-Khandan et al. 2016; Shimwela et al. 2018), whereas associations with temperature were less straightforward.

The incubation period (the time from first infection until HLB symptom appearance) can vary tremendously (Shen et al. 2013b). Under controlled conditions, the incubation period of individual trees can range from 2 months to more than 6 months (Folimonova et al. 2009; Gottwald 2010). At the grove and regional scale, the incubation period can vary from several months to several years, depending on grove management, sampling intensity, and frequency (Shen et al. 2013b), as well as the kind of tissues (leaves or roots) sampled (Johnson et al. 2014). In our small-scale study with a 6-month sampling frequency of systematically selected trees in a block, HLB symptom development was monitored on individual trees, and the time from first detection of ' $\mathrm{Ca}$. L. asiaticus' in the foliage to first symptom detection was 6 months or less. This period is similar to the incubation period under controlled conditions, although the time of first infection is unknown under natural field conditions. This information gap is a consequence of the total lack of ACP invasion studies over time for given groves. It is striking that, at the grove scale, ' $C a$. L. asiaticus'-positive psyllids were detected 6 years before the first symptoms were observed at the eastern edge of this grove (Shen et al. 2013b). Also, at the landscape scale, positive ACP were found months to years prior to symptom development (Manjunath et al. 2008). Before 2013, ' $\mathrm{Ca}$. L. asiaticus'-positive ACP were still rare in Northern Florida, citrus trees were generally still healthy, and experiments with ACP had to be carried out in BSL3 certified greenhouses. These circumstances were thought to be optimal for monitoring asymptomatic and symptomatic ' $\mathrm{Ca}$. L. asiaticus'-positive trees and estimating the apparent incubation period. However, the observation frequency was too low for a good estimate of the time between detectable ' $\mathrm{Ca}$. L. asiaticus' infection and symptom appearance. In future research, frequent monitoring of the same trees starting with healthy-looking trees may be warranted. Early monitoring is also important for effective HLB management (Craig et al. 2018). Furthermore, invasion studies are critical for deeper understanding of the dynamics of spread of HLB. Lee et al. (2015) indicated the sensitivity of the rate of advance of asymptomatic infection fronts to ACP invasion patterns but additional invasion studies are called for.

HLB-diseased trees often are more numerous initially at the edges of a grove; for example, adjacent to open areas next to citrus plantations (Gottwald et al. 2010; Leal et al. 2010; Luo et al. 2012; Martini et al. 2015). In our small-scale study, the epidemic front moved from east (with a road and open fields) to west across the citrus rows. A westward trend was also initially observed in the commercial groves in South Florida. The east-to-west movement of ACP and HLB had been observed in other areas at the beginning of HLB epidemics (Flores-Sánchez et al. 2017) (S.E. Halbert and M. W. Brodie, unpublished data). Further movement of the epidemic front within groves primarily depends on the orientation of the rows, moving across rows from the edge where the pathogen was introduced by infective ACP (Gottwald et al. 2007). This also was observed in our study at Citra, where the row orientation is

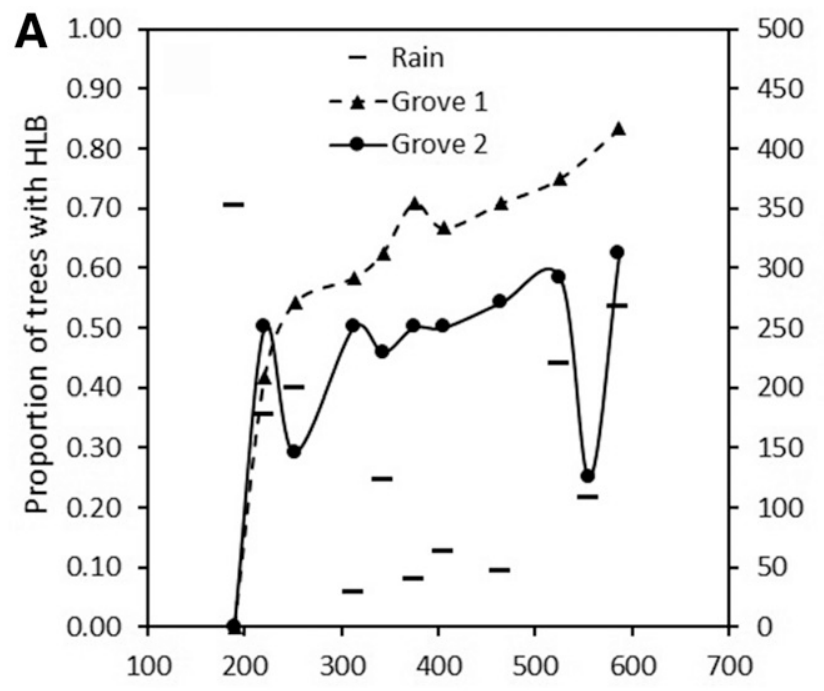

Days since 1-1-2009

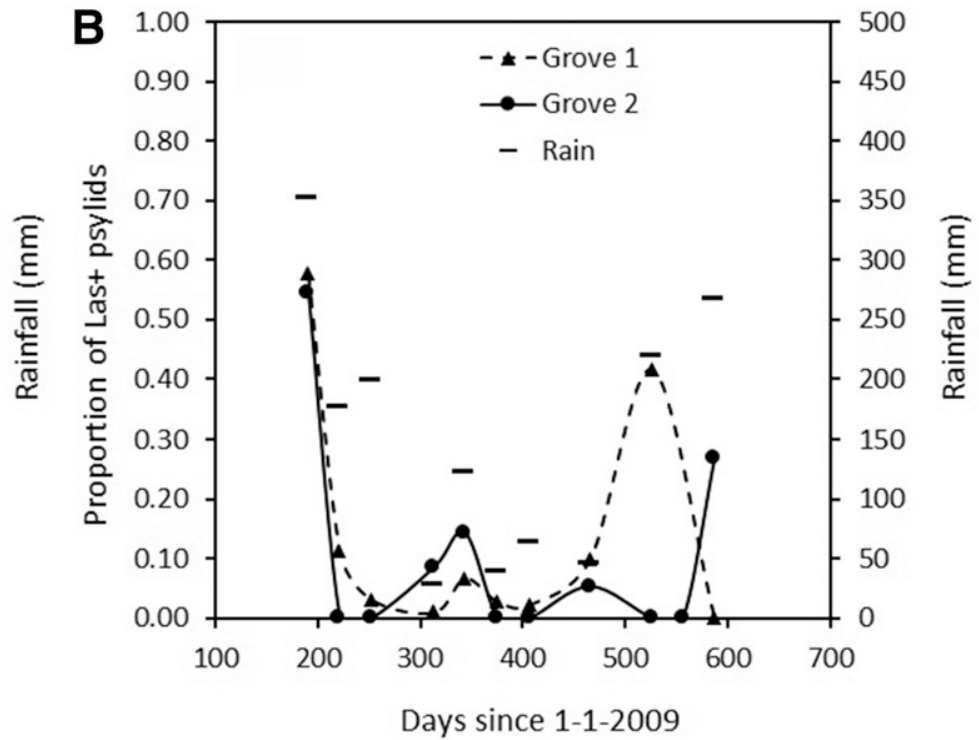

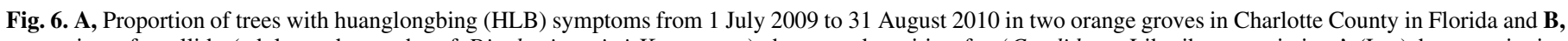

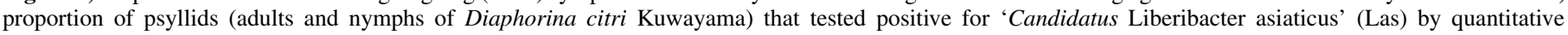

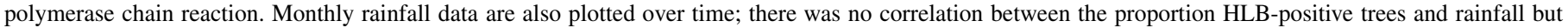
there was a positive correlation between the proportion ' $\mathrm{C}$. L. asiaticus'-positive psyllids and rainfall during the previous month. 
north-to-south (Shen et al. 2013b). The east-to-west direction of ACP movement could also be explained by the light source (the sun) from the southwest in the afternoon, when most flight activity is observed (Sétamou et al. 2011).

In the small grove at Citra, the dispersal was initially gradual but then became discontinuous, with several rows skipped, possibly because ' $\mathrm{Ca}$. L. asiaticus'-positive psyllids jumped when citrus trees declined on the east side of the grove, providing insufficient nutrients and resulting in intraspecific competition (Hall and Hentz 2011; Lewis-Rosenblum et al. 2015; Udell et al. 2017). An additional disturbing factor leading to psyllid movement could have been the death of HLB-infected citrus trees after a period of night frost in February 2013 (Gottwald et al. 2007; Hall et al. 2011) (https://ucanr.edu/sites/gardenweb/files/29080.pdf). ACP develops larger wings at relatively low temperatures (Paris et al. 2017). Additional introductions of infective psyllids from the west side with the wind are unlikely, because there were no infected trees in that area. An adjacent citrus block on the west side of the sampled block was still free from detectable ' $\mathrm{Ca}$. L. asiaticus' at the end of our study but HLB continued to move westward into the adjacent block after 2014 (unpublished observations). East-to-west movement of ACP and HLB were also observed by Flores-Sánchez et al. (2017). Introductions at random locations, as assumed in some simulation models (Lee et al. 2015), may not be common in reality.

For the first time, we showed that the rate of the epidemic front was similar for the ' $\mathrm{Ca}$. L. asiaticus'-infected asymptomatic trees as for the HLB-symptomatic trees (approximately $3 \mathrm{~m} \mathrm{month}^{-1}$ ). At this rate, approximately half of the trees were ' $\mathrm{Ca}$. L. asiaticus' positive in 2 years. Based on an individual-based microsimulation model, Lee et al. (2015) predicted that all trees in this grove would be asymptomatically infected within 1 or 2 years. The difference between the observed and calculated rate of spread could be due to the difficulty of detecting ' $C a$. L. asiaticus' resulting from its uneven distribution in infected trees and possibly because the pathogen was initially concentrated in the roots (Gottwald 2010; Johnson et al. 2014).

The third major finding of the present study was the absence of a direct spatial relationship between (' $\mathrm{C} a$. L. asiaticus'-positive) ACP populations and HLB incidence in two adjacent commercial groves. Finding a spatiotemporal relationship between ' $\mathrm{Ca}$. L. asiaticus'positive ACP populations and HLB symptoms may have been hampered by the lack of a complete census of susceptible trees and associated psyllids in the area. In addition, ACP populations change at very small spatial and temporal scales (viz., at flush and monthly scales) (Chiyaka et al. 2012; Lee et al. 2015), whereas HLB symptoms change very slowly at whole-tree and annual scales. For these reasons, a direct relationship between ACP populations (even ' $C a$. L. asiaticus'-positive ACP populations) and HLB symptom development may remain obscure, and detailed spatial monitoring of ' $\mathrm{Ca}$. L. asiaticus'-positive ACP may be less useful when modeling this disease than monitoring infected asymptomatic trees. Due to HLB's long and variable incubation period, symptomatic trees would be less reliable indicators of infection events than ' $C a$. L. asiaticus'-positive asymptomatic trees (Lee et al. 2015; Shen et al. 2013b). Cunniffe et al. (2015) argued that it is not necessary to track psyllid populations to model HLB spread, because these factors could be included in the dispersal and infection rate parameters of a model. However, more detailed studies of psyllid invasion patterns and ' $C a$. L. asiaticus'-positive asymptomatic trees could be useful for the prediction of asymptomatic and symptomatic epidemic fronts in areas where ACP and ' $\mathrm{Ca}$. L. asiaticus' were detected but are not

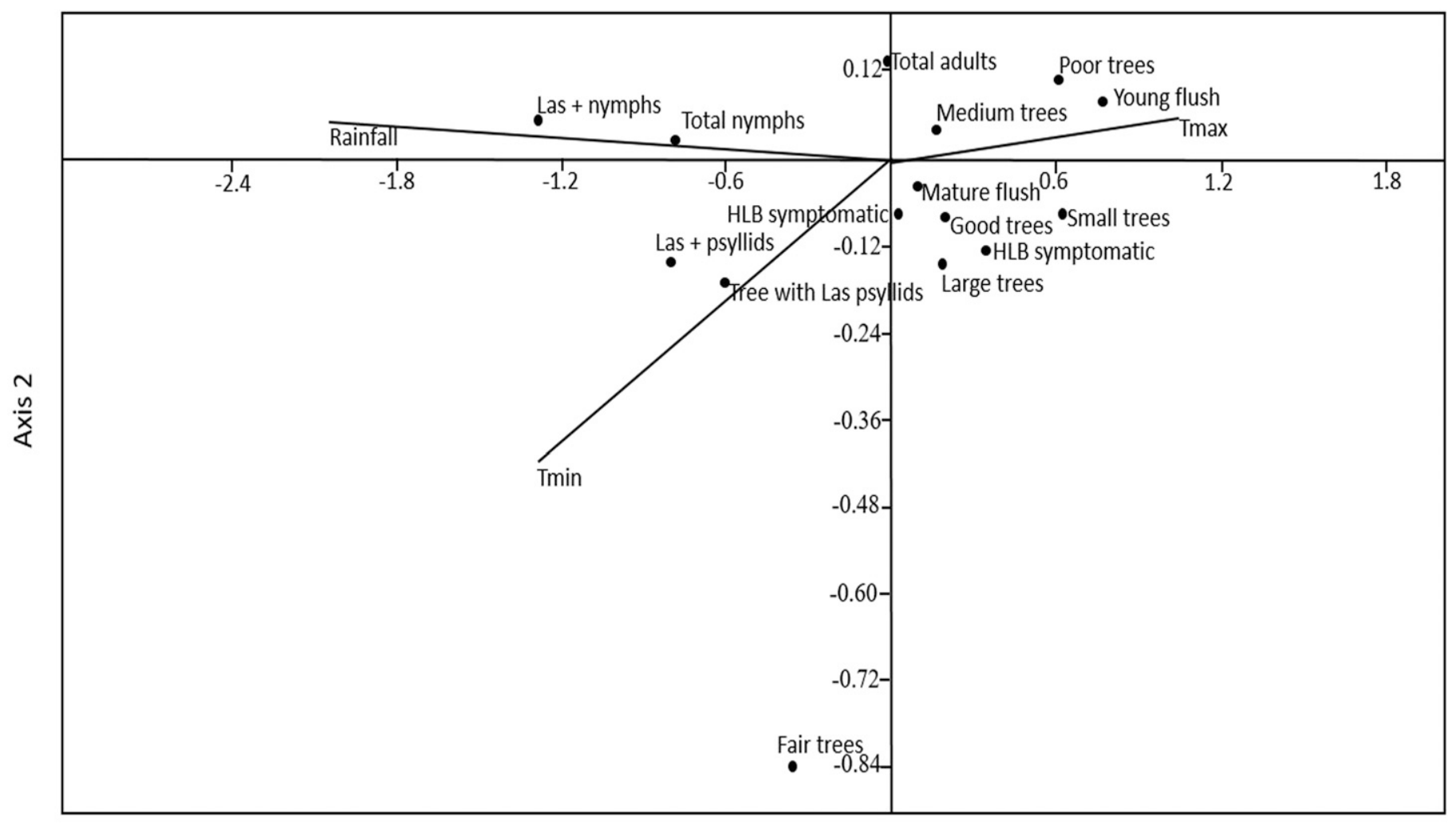

Axis 1

Fig. 7. Canonical correspondence analysis on monthly data of total populations of adult and immature Asian citrus psyllids, Diaphorina citri Kuwayama, and populations that tested positive for 'Candidatus Liberibacter asiaticus' (Las) by quantitative polymerase chain reaction, the general health status and size of orange trees, the number of mature and young flush, and the presence of typical HLB symptoms. Monthly rainfall, minimum temperature, and maximum temperature were also included. The analysis was carried out using the Past program, version 3.11. 
yet widespread. Root testing might provide even earlier detection of infected plants (Johnson et al. 2014).

Fourth, the positive association between HLB incidence, ' $\mathrm{Ca}$. L. asiaticus'-positive trees or ' $\mathrm{Ca}$. L. asiaticus'-positive ACP, and rainfall during the previous month in both studies reinforced similar findings at the regional and global scales (Narouei-Khandan et al. 2016; Shimwela et al. 2018). In two other Florida studies, ACP abundance and ' $\mathrm{Ca}$. L. asiaticus'-positive ACP populations were highest during the summer and fall, when rainfall and minimum temperatures are relatively high (Parkunan et al. 2011; Tsai et al. 2002). On the other hand, ACP dispersal was highest in spring and summer in Florida but these ACP were not necessarily ' $C a$. L. asiaticus' positive (Hall and Hentz 2011; Lewis-Rosenblum et al. 2015). Elsewhere, ACP populations and ' $\mathrm{Ca}$. L. asiaticus' titers in ACP were also positively correlated with rainfall (Teck et al. 2011). Despite positive correlations between rainfall and populations of infective psyllids as well as the regional occurrence of HLB, rainfall is currently not included as an environmental factor in risk-based survey methods (Gottwald et al. 2014; Parnell et al. 2014) (http:// www.plantmanagementnetwork.org/edcenter/seminars/outreach/ Citrus/HLB/presentation.html). However, rainfall could possibly be useful when assessing risks in areas with highly variable rainfall, such as California (Narouei-Khandan et al. 2016; Shimwela et al. 2018).

Seasonally high populations of ACP adults and nymphs have been attributed often to abundant flush production during rainy seasons (Lewis-Rosenblum et al. 2015; Torres-Pacheco et al. 2013; Udell et al. 2017). In our study in South Florida, there was abundant flush after an increase in minimum and maximum temperatures in early spring but this was not associated with high ACP populations ('Ca. L. asiaticus'-positive or not). In several other studies in Florida and some tropical countries, a clear, direct relationship between flush abundance and ACP populations was also missing (Hall and Hentz 2011; Razi et al. 2014; Teck et al. 2011). However, a positive correlation between flush abundance and ACP populations sometimes was found at lags of 4 to 6 weeks (Udell et al. 2017). Hall (2018) and Suaste-Dzul et al. (2017) observed the highest pathogen concentrations in ACP in fall and winter or winter and spring, respectively, rather than summer (associated with inhibiting high summer temperatures at that time) but, in several other studies in Florida, populations of ' $\mathrm{Ca}$. L. asiaticus'-positive ACP were highest in summer and fall (Irey et al. 2011; Parkunan et al. 2011; Shimwela et al. 2018). 'Ca. L. asiaticus'-positive ACP populations were positively associated with rainfall in these studies, whereas total ACP numbers were not. High ' $\mathrm{Ca}$. L. asiaticus' concentrations in ACP may be associated with a physiological response of citrus trees to rain (wetting the deep roots), bringing carbohydrates and ' $\mathrm{Ca}$. L. asiaticus' from deep roots up to new foliage (Johnson et al. 2014), resulting in the accumulation of ' $C a$. L. asiaticus' in the foliage, which was highest in summer and fall (Irey et al. 2011; Parkunan et al. 2011).

Although the incidence of HLB-affected trees and ' $\mathrm{Ca}$. L. asiaticus'-positive ACP in our studies were not directly correlated with temperatures during the month prior to disease and vector observations, canonical correspondence analysis indicated that minimum temperature was associated positively with numbers of trees with ' $\mathrm{Ca}$. L. asiaticus'-positive ACP and the numbers of ' $\mathrm{Ca}$. L. asiaticus'-positive ACP per tree in the two groves in South Florida. Minimum temperature was positively correlated with rainfall ( $r=0.55 ; P=0.01)$ but ' $C a$. L. asiaticus'-positive ACP nymphs were more strongly associated with rainfall than with minimum temperature. In the small grove in northern Florida, the half-yearly increases in ' $\mathrm{Ca}$. L. asiaticus'-positive trees and HLBsymptomatic trees were associated with average temperatures during the 6 months prior to observation but these relationships were less clear than those with rainfall. Thus, the results on associations of HLB and ACP with weather variables must be considered as tentative due to the limited number of time points in both studies.
In conclusion, spatiotemporal monitoring of ' $\mathrm{Ca}$. L. asiaticus' infection of citrus trees and ACP at the grove scale resulted in information that could be useful for modeling the spread of ACP and HLB, including estimations of the rate of frontal movement and the period from detectable infection to symptom expression. However, much more frequent and detailed observations would be needed at a much finer scale to analyze and predict the invasion pattern and wave fronts of ACP and HLB in citrus groves. This kind of study would not be possible anymore in Florida and other areas where HLB is already widespread. More detailed studies are also needed on the effects of deep wetting by rain as opposed to superficial wetting by irrigation on the movement of ' $\mathrm{Ca}$. L. asiaticus' in citrus trees in order to better understand epidemic development within and among citrus trees (Chiyaka et al. 2012; Shimwela et al. 2018).

\section{ACKNOWLEDGMENTS}

We thank J. Boyer and his crew for maintaining the small citrus grove in Citra and providing information about the management of that grove; E. Dickstein, H. L. Er, S. Shakya, K. Sharma, and W. Shen for help with disease scoring and leaf sampling in Citra; M. Laprete for help with lab work; the excellent crew who collected the data on tree characteristics, HLB symptoms, and psyllids in the two neighboring groves in South Florida: S. Estrada, M. Cruz (formerly M. Olvera), E. M. Resendiz, M. Zuniga, S. Valdez, Y. Hernandez, A. Ramirez, and T. Gutierrez; H. Fahsbender and H. Narouei-Khandan for transferring the data from paper forms into Excel spread sheets; and K. Shin and S. Timilsina for providing independent reviews of the manuscript. The opinions expressed herein are those of the author(s) and do not necessarily reflect the views of the U.S. Agency for International Development or the United States Government.

\section{LITERATURE CITED}

Aurambout, J. P., Finlay, K. J., Luck, J., and Beattie, G. A. C. 2009. A concept model to estimate the potential distribution of the Asiatic citrus psyllid Diaphorina citri Kuwayama in Australia under climate change-A means for assessing biosecurity risk. Ecol. Modell. 220:2512-2524.

Bassanezi, R. B., Busato, L. A., Bergamin Filho, A., Amorim, L., and Gottwald, T. R. 2005. Preliminary spatial pattern analysis of huanglongbing in São Paulo, Brazil. Pages 341-355 in: Sixteenth IOCV Conf., Monterrey, Mexico.

Bonani, J. P., Fereres, A., Garzo, E., Miranda, M. P., Appezzato-Da-Gloria, B., and Lopes, J. R. S. 2010. Characterization of electrical penetration graphs of the Asian citrus psyllid, Diaphorina citri, in sweet orange seedlings. Entom. Exp. Appl. 134:35-49.

Bouwmeester, H., Heuvelink, G. B. M., and Stoorvogel, J. J. 2016. Mapping crop diseases using survey data: The case of bacterial wilt in bananas in the East African highlands. Eur. J. Agron. 74:173-184.

Bové, J. 2014. Heat-tolerant Asian HLB meets heat-sensitive African HLB in the Arabian Peninsula! Why? J. Citrus Pathol 1:1-78. https://escholarship. org/uc/item/1665n $4 \times 9$

Chiyaka, C., Singer, B. H., Halbert, S. E., Morris, J. G., and van Bruggen, A. H. C. 2012. Modeling huanglongbing transmission within a citrus tree. Proc. Nat. Acad. Sci. 109:12213-12218.

Craig, A. P., Cunniffe, N. J., Parry, M., Laranjeira, F. F., Gilligan, C. A. 2018. Grower and regulator conflict in management of the citrus disease Huanglongbing in Brazil: A modelling study. J. Appl. Ecol. 0:1956-1965.

Cunniffe, N. J., Koskella, B., Metcalf, C. J. E., Parnell, S., Gottwald, T. R., and Gilligan, C. A. 2015. Thirteen challenges in modelling plant diseases. Epidemics 10:6-10.

da Graça, J. V., Douhan, G. W., Halbert, S. E., Keremane, M. L., Lee, R. F., Vidalakis, G., and Zhao, H. 2016. Huanglongbing: An overview of a complex pathosystem ravaging the world's citrus. J. Integr. Plant Biol. 58:373-387.

Ebert, T. A., Backus, E. A., Shugart, H. J., and Rogers, M. E. 2018. Behavioral plasticity in probing by Diaphorina citri (Hemiptera, Liviidae): Ingestion from phloem versus xylem is influenced by leaf age and surface. J. Insect Behav. 31:119-137.

Farnsworth, D., Grogan, K. A., van Bruggen, A. H. C., and Moss, C. B. 2014. The potential economic cost and response to greening in Florida citrus. Choices 29:1-6.

Flores-Sánchez, J. L., Mora-Aguilera, G., Loeza-Kuk, E., López-Arroyo, E. I., Gutiérrez-Espinosa, M. A., Vélazquez-Monreal, J. J., Domínguez-Monge, S., Bassanezi, R. B., Acevedo-Sánchez, G., and Robles-García, P. 2017. Diffusion model for describing the regional spread of huanglongbing from first-reported outbreaks and basing an area-wide disease management strategy. Plant Dis. 101:1119-1127. 
Folimonova, S. Y., Robertson, C. J., Garnsey, S. M., Gowda, S., and Dawson, W. O. 2009. Examination of the responses of different genotypes of citrus to Huanglongbing (citrus greening) under different conditions. Phytopathology 99:1346-1354.

Fujikawa, T., Miyata, S.-I., and Iwanami, T. 2013. Convenient detection of the Citrus Greening (Huanglongbing) bacterium 'Candidatus Liberibacter asiaticus' by direct PCR from the midrib extract. PLoS One 8:e57011.

Gasparoto, M. C., Hau, B., Bassanezi, R. B., Rodrigues, J. C., and Amorim, L. 2018. Spatio-temporal dynamics of citrus Huanglongbing spread: A case study. Plant Pathol. 67:1621-1628.

Gottwald, T. R. 2010. Current epidemiological understanding of citrus huanglongbing. Annu. Rev. Phytopathol. 48:119-139.

Gottwald, T. R., da Graça, J. V., and Bassanezi, R. B. 2007. Citrus huanglongbing: The pathogen and its impact. Online publication. Plant Health Prog. 8.

Gottwald, T. R., Irey, M. S., Gast, T., Parnell, S. R., Taylor, E. L., and Hilf, M. E. 2010. Spatio-temporal analysis of an HLB epidemic in Florida and implications for spread. Pages 84-97 in: Proc. 17th Conference IOCV, Adana, Turkey.

Gottwald, T. R., Luo, W., and McRoberts, N. 2014. Risk-based residential HLB/ ACP survey for California, Texas and Arizona. J. Citrus Pathol. 1:121-125.

Grafton-Cardwell, E. E., Stelinski, L. L., and Stansly, P. A. 2013. Biology and management of Asian citrus psyllid, vector of huanglongbing pathogens. Annu. Rev. Entomol. 58:413-432.

Gutierrez, A. P., and Ponti, L. 2013. Prospective analysis of the geographic distribution and relative abundance of Asian citrus psyllid (Hemiptera: Liviidae) and citrus greening disease in North America and the Mediterranean Basin. Fla. Entomol. 96:1375-1391.

Hall, D. G. 2018. Incidence of "Candidatus Liberibacter asiaticus" in a Florida population of Asian citrus psyllid. J. Appl. Entomol. 142:97-103.

Hall, D. G., and Hentz, M. G. 2011. Seasonal flight activity by the Asian citrus psyllid in east central Florida. Entomol. Exp. Appl. 139:75-85.

Hall, D. G., Richardson, M. L., Ammar, E.-D., and Halbert, S. E. 2012. Asian citrus psyllid, Diaphorina citri, vector of citrus huanglongbing disease. Entomol. Exp. Appl. 146:207-223.

Hall, D. G., Wenninger, E. J., and Hentz, M. G. 2011. Temperature studies with the Asian Citrus Psyllid, Diaphorina citri: Cold hardiness and temperature thresholds for oviposition. J. Insect Sci. 11:1-15.

Hussain, M., Lin, Y., and Wang, L. 2017. Effect of temperature on longevity of Diaphorina citri (Hemiptera: Liviidae) studied by microcalorimeter. J. Therm. Anal. Calorim. 127:1245-1252.

Irey, M. S., Gast, T., Cote, J., Gadea, P., Santiago, O., Briefman, L., and Graham, J. H. 2011. Seasonal variability in HLB testing data in plant and psyllid samples in Florida. In: Second Int. Res. Conf. Huanglongbing (IRCHLB), Orlando, FL USA.

Johnson, E. G., Wu, J., Bright, D. B., and Graham, J. H. 2014. Association of 'Candidatus Liberibacter asiaticus' root infection, but not phloem plugging with root loss on huanglongbing-affected trees prior to appearance of foliar symptoms. Plant Pathol. 63:290-298.

Johnston, K., VerHoef, J. M., Krivoruchko, K., and Lucas, N. 2001. Using ArcGIS Geostatistical Analyst. ESRI, New York.

Leal, R. M., Barbosa, J. C., Gregolin Costa, M., Belasque, J., Jr., Yamamoto, P. T., and Dragone, J. 2010. Distribuição espacial de huanglongbing (greening) em citros utilizando a geoestatística [Spatial distribution of huanglongbing (greening) on citrus using geostatistic]. Rev. Bras. Frutic. 32:808-818.

Lee, J. A., Halbert, S. E., Dawson, W. O., Robertson, C. J., Keesling, J. E., and Singer, B. H. 2015. Asymptomatic spread of huanglongbing and implications for disease control. Proc. Natl. Acad. Sci. USA 112:7605-7610.

Lewis-Rosenblum, H., Martini, X., Tiwari, S., and Stelinski, L. L. 2015. Seasonal movement patterns and long-range dispersal of Asian citrus psyllid in Florida citrus. J. Econ. Entomol. 108:3-10.

Li, W., Levy, L., and Hartung, J. S. 2006. Quantitative real-time PCR for detection and identification of Candidatus Liberibacter species associated with citrus huanglongbing. J. Microbiol. Methods 66:104-115.

Li, W., Levy, L., and Hartung, J. S. 2009. Quantitative distribution of 'Candidatus Liberibacter asiaticus' in citrus plants with citrus huanglongbing. Phytopathology 99:139-144.

López-Collado, J., López-Arroyo, J. I., Robles-García, P. L., and Márquez-Santos, M. 2013. Geographic distribution of habitat, development, and population growth rates of the Asian citrus psyllid, Diaphorina citri, in Mexico. J. Insect Sci. 13:114

Luo, W., Pietravalle, S., Parnell, S., van den Bosch, F., Gottwald, T. R., Irey, M. S., and Parker, S. R. 2012. An improved regulatory sampling method for mapping and representing plant disease from a limited number of samples. Epidemics 4:68-77.

Manjunath, K. L., Halbert, S. E., Ramadugu, C., Webb, S., and Lee, R. F. 2008. Detection of Candidatus Liberibacter asiaticus' in Diaphorina citri and its importance in the management of citrus huanglongbing in Florida. Phytopathology 98:387-396.

Martini, X., Pelz-Stelinski, K. S., and Stelinski, L. L. 2015. Absence of windbreaks and replanting citrus in solid sets increase density of Asian citrus psyllid populations. Agric. Ecosyst. Environ. 212:168-174.
Narouei-Khandan, H. A., Halbert, S. E., Worner, S. P., and van Bruggen, A. H. C. 2016. Global climate suitability of citrus huanglongbing and its vector, the Asian citrus psyllid, using two correlative species distribution modeling approaches, with emphasis on the USA. Eur. J. Plant Pathol. 144: 655-670.

Nelson, T. A., and Boots, B. 2008. Detecting spatial hot spots in landscape ecology. Ecography 31:556-566.

Paris, T. M., Allan, S. A., Hall, D. G., Hentz, M. G., Croxton, S. D., Ainpudi, N., and Stansly, P. A. 2017. Effects of temperature, photoperiod, and rainfall on morphometric variation of Diaphorina citri (Hemiptera: Liviidae). Environ. Entomol. 46:143-158.

Parkunan, V., Ebert, T., Wang, N., Rogers, M., and Dewdney, M. 2011. Seasonal variation of Candidatus Liberibacter asiaticus in citrus branches and in vector, Diaphorina citri, in central Florida sweet orange groves. (Abstr.) Phytopathology 101:S138.

Parnell, S., Gottwald, T. R., Irey, M. S., Luo, W., and van den Bosch, F. 2011. A stochastic optimization method to estimate the spatial distribution of a pathogen from a sample. Phytopathology 101:1184-1190.

Parnell, S., Gottwald, T. R., Riley, T., and van den Bosch, F. 2014. A generic riskbased surveying method for invading plant pathogens. Ecol. Appl. 24:779-790.

Razi, M. F., Keremane, M. L., Ramadugu, C., Roose, M., Khan, I. A., and Lee, R. F. 2014. Detection of citrus Huanglongbing-Associated 'Candidatus Liberibacter asiaticus' in citrus and Diaphorina citri in Pakistan, seasonal variability, and implications for disease management. Phytopathology 104: 257-268.

Savary, S., Madden, L. V., Zadoks, J. C., and Klein-Gebbinck, H. W. 1995. Use of categorical information and correspondence analysis in plant disease epidemiology. Adv. Bot. Res. 21:213-240.

Sétamou, M., Sanchez, A., Patt, J. M., Nelson, S. D., Jifon, J., and Louzada, E. F. 2011. Diurnal patterns of flight activity and effects of light on host finding behavior on the Asian citrus psyllid. J. Insect Behav. 25:264-276.

Sétamou, M., Simpson, C. R., Alabi, O. J., Nelson, S. D., Telagamsetty, S., and Jifon, J. L. 2016. Quality matters: Influences of citrus flush physicochemical characteristics on population dynamics of the Asian Citrus Psyllid (Hemiptera: Liviidae). PLoS One 11:e0168997.

Shen, W., Cevallos-Cevallos, J. M., Nunes da Rocha, U., Stansly, P. A., Roberts, P. D., and van Bruggen, A. H. C. 2013a. Relation between plant nutrition, hormones, insecticide applications, bacterial endophytes, and Candidatus Liberibacter $\mathrm{Ct}$ values in citrus trees infected with huanglongbing. Eur. J. Plant Pathol. 137:727-742.

Shen, W., Halbert, S. E., Dickstein, E., Manjunath, K. L., Shimwela, M. M., and van Bruggen, A. H. C. 2013b. Occurrence and in-grove distribution of citrus huanglongbing in north central Florida. J. Plant Pathol. 95:361-371.

Shimwela, M. M., Narouei Khandan, H. A., Halbert, S. E., Keremane, M. L., Minsavage, G. V., Timilsina, S., Massawe, D. P., Jones, J. B., and van Bruggen, A. H. C. 2016. First occurrence of Diaphorina citri in East Africa, characterization of the $\mathrm{Ca}$. Liberibacter species causing huanglongbing (HLB) in Tanzania, and potential further spread of D. citri and HLB in Africa and Europe. Eur. J. Plant Pathol. 146:349-368.

Shimwela, M. M., Schubert, T., Albritton, M., Halbert, S. E., Jones, D. J., Sun, X., Roberts, P. D., Singer, B. H., Lee, W. S., Jones, J. B., Ploetz, R. C., and van Bruggen, A. H. C. 2018. Regional spatial-temporal spread of citrus huanglongbing is affected by rain in Florida. Phytopathology 108: $1420-1428$.

Smith, M. J., Goodchild, M. F., and Longley, P. A. 2007. Geospatial Analysis: Comprehensive Guide to Principles, Techniques and Software Tools. Matador, Leicester, UK.

Suaste-Dzul, A., Gallou, A., Félix-Portillo, M., Moreno-Carrillo, G., Sánchez-González, J., Palomares-Pérez, M., and Arredondo-Bernal, H. 2017. Seasonal incidence of 'Candidatus Liberibacter asiaticus' (Rhizobiales: Rhizobiaceae) in Diaphorina citri (Hemiptera: Liviidae) in Colima, Mexico. Trop. Plant Pathol. 42:410-415.

Teck, S. L. C., Fatimah, A., Beattie, A., Heng, R. K. J., and King, S. 2011. Seasonal population dynamics of the Asian citrus psyllid, Diaphorina citri Kuwayama in Sarawak. Am. J. Agric. Biol. Sci. 6:527-535.

Thomas, S. M., Simmons, G. S., and Daugherty, M. P. 2017. Spatiotemporal distribution of an invasive insect in an urban landscape: Introduction, establishment and impact. Landsc. Ecol. 32:2041-2057.

Torres-Pacheco, I., López-Arroyo, J., Aguirre-Gómez, J., Guevara-González, R., Yänez-López, R., Hernández-Zul, M., and Quijano-Carranza, J. 2013. Potential distribution in Mexico of Diaphorina citri (Hemiptera: Psyllidae) vector of huanglongbing pathogen. Fla. Entomol. 96:36-47.

Tsai, J. H., Wang, J. J., and Liu, Y. H. 2002. Seasonal abundance of the Asian citrus psyllid, Diaphorina citri (Homoptera: Psyllidae) in southern Florida. Fla. Entomol. 85:446-451.

Udell, B. D., Monzo, C., Paris, T. M., Allan, S. A., and Stansly, P. A. 2017. Influence of limiting and regulating factors on populations of Asian citrus psyllid and the risk of insect and disease outbreaks. Ann. Appl. Biol. 171: 70-88. 